\title{
Landscape practise and key concepts for landscape sustainability
}

Brandt, Jesper; Christensen, Andreas Aagaard; Svenningsen, Stig Roar; Holmes, Esbern

Published in:

Landscape Ecology

DOI:

10.1007/s10980-012-9777-5

Publication date:

2013

Document version

Early version, also known as pre-print

Citation for published version (APA):

Brandt, J., Christensen, A. A., Svenningsen, S. R., \& Holmes, E. (2013). Landscape practise and key concepts for landscape sustainability. Landscape Ecology, 28(6), 1125-1137. https://doi.org/10.1007/s10980-012-9777-5 


\title{
Landscape practise and key concepts for landscape sustainability
}

\author{
Jesper Brandt • Andreas Aagaard Christensen • \\ Stig Roar Svenningsen • Esbern Holmes
}

Received: 27 September 2011/Accepted: 4 July 2012/Published online: 10 August 2012

(C) Springer Science+Business Media B.V. 2012

\begin{abstract}
Conceptual frameworks which have seen man and nature as being an integrated whole were widespread before they became suppressed by developments within both capitalism and socialism. Therefore an idealistic use of such concepts in scientific work has often had limited practical value. At the same time, the practice behind such conceptual frameworks has survived in many land use systems, being a fundamental source of inspiration for the modern challenge of landscape sustainability. Here, the concept and practice of carrying capacity is used as an example. We provide a modern interpretation and relate it to an empirical study of sustainable tourism in eight protected areas and their regions in the Baltic. They are subject to large differences in human pressure. The political commitment to the related EU Natura 2000 networks has been taken as our point of departure for a more detailed analysis of accessibility and its related conflicts, and opportunities for a
\end{abstract}

J. Brandt $(\bowtie) \cdot$ E. Holmes

Department of Environmental, Social and Spatial Change (ENSPAC), Roskilde University, 4000 Roskilde, Denmark

e-mail: brandt@ruc.dk

\section{A. A. Christensen}

Faculty of Life Sciences, University of Copenhagen,

2100 Frederiksberg, Denmark

\section{S. R. Svenningsen}

The Royal Library, Map, Prints and Photographs, 1610 Copenhagen, Denmark sustainable development of tourism in and around the protected areas. It is concluded that the concept of carrying capacity cannot meaningfully be used for sustainability studies at an abstract conceptual level, but proves its relevance through a detailed context specific analyses of visitor related conflicts.

Keywords Protected areas - Nature parks . Natura 2000 - Visitor carrying capacity · Sustainable landscapes · European Landscape Convention · Sustainable regional development · Case study · Landscape accessibility

\section{The dialectics between man and nature in theory and in practice}

In developing a research agenda, the term 'key concepts' will always have a high priority since a conceptual and methodological research framework is considered an essential part of scientific activity in the related research community. It is thus only natural that issues surrounding key concepts have been raised within landscape ecology at regular intervals since the foundation of the International Association for Landscape Ecology (IALE) in 1982.

This happened, for example, at the IALE European Congress in Preston, UK, in August 1998. The conference was entitled 'Key Concepts in Landscape 
Ecology'. Here it became clear that an important source of conceptual innovation was the pressure on the community of landscape ecologists from landscape practice (Brandt 1998). This trend has been reinforced by landscape ecology's emerging agenda as an integrative scientific foundation for the study of landscape sustainability (Wu and Hobbs 2002; Potschin and Haines-Young 2006; Wiens 2009).

Several of those contributing to these efforts have emphasized the conceptual importance of cultural issues (Musacchio 2009a; Wu 2010) and philosophical considerations for the study and practice of landscape sustainability (examples include 'the six Es for design of landscape sustainability' (Musacchio 2009b), and the classic Chinese philosophy of 'unity of man with nature' (Chen and Wu 2009). However, such an interest might also be accompanied by a certain philosophical idealism in which the development of concepts is in general seen as the foundation for social practice. Thus the development of key concepts is seen as a main task in the endeavor to develop sustainable landscapes. As scientists we certainly tend to work in that way. Our scientific ideal is still the hunt for global regularity and design principles, namely rules and concepts which can be applied in our everyday lives.

It should however also be recognized that, historically, the connection between concepts and social practice has in general been the other way around: social practice and the prevailing power relations have in most cases determined or at least significantly reshaped any philosophical system to adapt it to the existing social system.

Integrated conceptual systems, which Chen and $\mathrm{Wu}$ (2009) recommend as an important concept for landscape ecology and landscape sustainability, have indeed been widespread in former times all over the world, not only in China and USA, but also in Europe.

However the development of capitalism deeply influenced western philosophy producing dichotomies between nature and culture which supported a dominating and conquering relationship of man over nature.

This was the fate of socialism as well. In classical Marxism, the unity of man and nature is a fundamental issue that Karl Marx presented as a general frame for understanding the contradictory capitalist development to which the working class historically had to put an end (Marx 1867/1967). Friedrich Engels described almost poetically the development of socialism as the initiation of man's reconciliation with nature and with himself.

But in the 1930s and during the Cold War there was no room for atonement with nature, nor, for that matter, even with man himself. Tough competition between East and West produced a forced exploitation of nature and man. By excluding the work object (the most relevant aspect of nature to man) from Marx's definition of the productive forces, Stalin (1938) and Mao (1937/1990) misinterpreted Marx and saw a sharp dichotomy between man and a nature that had to be conquered by all means possible. Mao's Great Leap Forward was an extreme result of this ideology, in part with catastrophic results.

Was all the classical wisdom, both from Chinese 'unity of man with nature' and from western philosophy, during this modern period suddenly forgotten?

Certainly not, a more detailed examination of local practice might reveal that ideology on the man-nature relation is not a prerequisite for sustainable landscape management.

Figure 1 shows the terraces of the famous Chinese village Dazhai, located some $5 \mathrm{~h}$ by train from Beijing. The fame of Dazhai comes from Mao Zedong's use of the village in his propaganda during the Great Leap Forward: 'In agriculture, learn from Dazhai'. The inhabitants of Dazhai had made a tremendous effort during the 1950s and 1960s to increase and stabilize production and improve village life. To Mao this represented the principle that 'For the purpose of attaining freedom in the world of nature, man must use natural science to understand, conquer and change nature and thus attain freedom from nature', Mao 1948, quoted in Zhao and Woudstra (2007). Zhao and Woudstra document the efforts made by the inhabitants of Dazhai, but also that they obviously did not change and conquer nature to attain freedom from it. The vast majority of the effort was put into the landscape outside the village to protect nature against accidental risks through comprehensive measures of greening and canalization. It was not just to raise production. The acreage of cultivation up through the 1950s was even consciously lowered in favor of additional woodland. Thus the purpose of raising the production was obviously subject to the purpose of risk minimization and conservation of the landscape, which would not have been the case if they had followed the Mao's simplified strategy. 


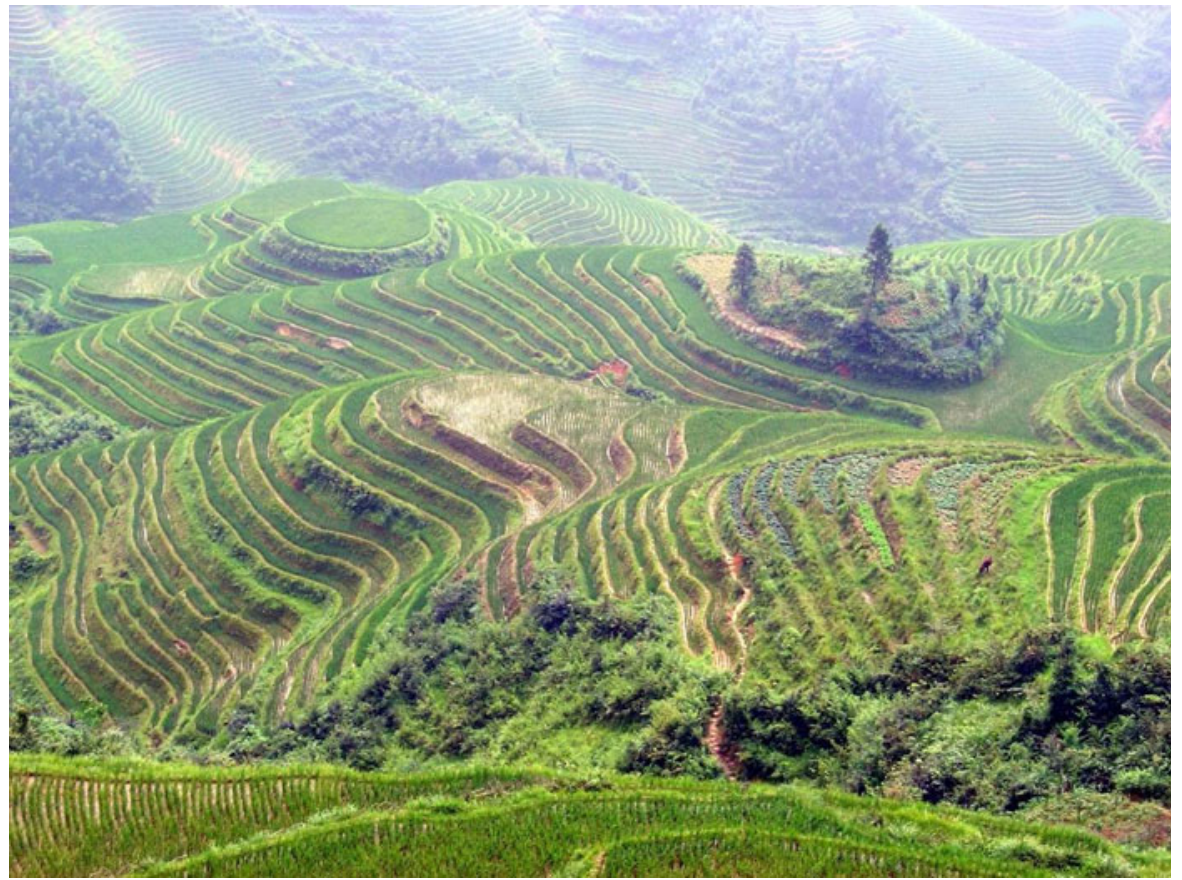

Fig. 1 View of terraces from Dazhai village in the eastern Shanxi Province in China, some $5 \mathrm{~h}$ by train from Beijing. Dazhai was an important model village during Mao Zedong's Great Leap Forward in the 1970s. Source http://blog.sanfo.

We doubt if the peasants of Dazhai had any bookish knowledge of classic Chinese philosophy concerning 'unity of man with nature': the village leader was an uneducated peasant, who, however, later became a minister. But the inhabitants were committed to hard work, collectivism and attachment to the land, which they had learned through practice and common sense.

The point of this case is that in the search for a research strategy for landscape sustainability we should prioritize empirical investigations and especially detailed case studies at least in parallel with conceptual constructions. This is especially relevant when landscape sustainability is being attached to the design of cultural landscapes (Musacchio 2009a; Wu 2010), to be studied and understood in a context of social science too. As the human geographer Bent Flyvbjerg has observed in a review of the case study method in The Sage Handbook of Qualitative Research, 'Social science has not succeeded in producing general, context-independent theory and has thus in the final instance nothing else to offer than concrete, context-dependent knowledge. And the case study is especially well suited to produce this knowledge' (Yin 1994; Flyvbjerg 2011).
com/user/\%B0\%A2\%B4\%A8/archives/2006/200651122848. shtml. The author of the blog is called "A-Chuan and Lisa", the photo taken by A-Chuan

\section{Globalization, local sustainability and landscape sustainability}

The challenges facing landscape ecology when dealing with key issues, concepts and priorities that are most important for landscape sustainability are, in practice, closely related to the process of globalization resulting from the demand for an open market as propagated by the World Trade Organisation (Brandt 2005). At the local/regional level, globalization constantly challenges the conditions for success on the market. From an economic point of view, it is thus relevant to describe sustainability as the ability to keep a territory's long run competitive positioning (Dallara and Rizzi 2012). Historically, the concept of sustainability was understood as carrying capacity, primarily related to the exploitation and management of a resource in a way that does not overcome a precise threshold related to its continuous renewal. Several types of resources could be involved, but mostly treated separately such as the carrying capacity for different types of grazing animals (Brandt 2010). However, the modern concept of sustainability 
focuses more on the inter-linkages between different types of carrying capacities and their combined positive or negative effect on an overall sustainable use of the natural and human resources related to a territory. With the advent of sustainability requirements following the Brundtland Report (World Commission on Environment and Development 1987) economic, social and environmental conditions for a territory's competitive position were placed on the agenda. Growing emphasis was devoted to the interrelations between these different systems related to a territory. From a territorial point of view, the need for sustainable development addresses "the health condition' of a territory by demanding an ecological balance in the fulfillment of human needs based on a good integration and co-evolution of the natural, economic and social subsystems of the territory.

For historical reasons such an integrated territorial understanding of local sustainability may have been particularly well developed in a densely populated Europe. Here a continuous reshaping of the varied cultural landscapes has given rise to complicated local connections between economic, social and environmental structures and potentials. These potentials have not only to be protected against any unilateral exploitation, but also to be mobilized and coordinated in a flexible multifunctional way if a sustainable competitive position on the world market is to be gained and maintained.

The sustainable development of the European landscapes has to be seen in this integrated context of continuity and competitive positioning in old cultural landscapes. As the adoption of the European Landscape Convention indicates, the conservation of cultural landscapes plays an important and growing role in Europe parallel to nature conservation. In Europe the realization of the biodiversity convention has been territorialized into the Natura 2000 system of protected areas at a European level. However, both the protection of nature and the cultural landscape is only to a limited degree made into something absolutely through the public acquisition of land. Rather landscape protection is designated in terms of intents for an area, to be developed in consultations with owners and interest groups. Here conservation is increasingly seen as a way to strengthen the cultural capability to ensure a continued sustainable multifunctional economic use of landscapes and the many and spatially varied ecosystem services offered by the landscape (Brandt and Vejre 2004). Thus conservation does not function as a model for spatial segregation into protected public and non-protected private land, as has normally been the case (for example in USA), where the modern tradition of carrying capacity studies relating to tourism in protected areas has been developed. In Europe, conservation is rather one among many means of regulation in a model of integrated sustainable management, with the option to be extrapolated in the management of the surrounding 'vernacular' landscapes. This restricts the use of the concept of carrying capacity as an overall management tool.

In the intensively used agricultural landscapes of Europe, a multifunctional mobilization of a broad range of landscape adapted ecosystem services is closely connected to the Common Agricultural Policy of the European Union, and the shift in agricultural funding from direct support for improving agricultural productivity towards a broader support for the environment and landscape in the agricultural areas (Brandt 2005). This not only implies a promotion of a more varied and multifunctional land use, but also a goal-oriented adaptation of land use to the potential ecosystem services of the landscape.

In the context of this endeavor, the spatial heterogeneity of landscapes at different scales plays a crucial role. From a peak of homogenization of land use in European agricultural landscapes in the 1970s, an adaptation to landscape heterogeneity at different spatial levels has developed as a means to improve the overall sustainability and a territorially balanced human-nature interaction. Both for the protection and the multifunctional use of the landscape, different types of accessibility at different spatial levels should be taken into account. This applies both to physical accessibility and different types of communicative accessibility (e.g. direct signage or indirect symbolic accessibility as well as legal accessibility related to property rights and legal rules for public access). In spatially heterogeneous landscapes, the potentials for both protection and a varied multifunctional land use are often considerable and mainly restricted by the ability of the community (1) to control spatial overexploitation, (2) to understand and mediate attitudes and potential priorities among different users of the landscape and (3) to mediate and manage the accessibility to the natural resources of the territory at lower spatial levels.

These priorities of sustainable development in European cultural landscapes are reflected in the 
European Landscape Convention, adopted by the European Council in 2001, according to which "Landscape" means an area, as perceived by people, whose character is the result of the action and interaction of natural and/or human factors (Council of Europe 2000)

Thus, the landscape convention considers the concept of landscape as both a material reality (to be studied by natural science and related empirical studies), and a social construct (to be studied by social sciences, humanities and design science). Further, according to the convention, "Landscape management" means action, from a perspective of sustainable development, to ensure the regular upkeep of a landscape, so as to guide and harmonise changes which are brought about by social, economic and environmental processes (Council of Europe 2000). Integrated planning, management and stakeholder involvement is mandatory for the successful implementation of the European Landscape Convention as a means to improve local life conditions and local competitive positioning (Semm and Palang 2010; Suškevičs and Külvik 2011; Stenseke and Jones 2011).

Landscape science within the tradition of natural science places emphasis on the study of structure and dynamics of landscape heterogeneity at different spatial levels. This tradition might play a growing role in the development of landscape sustainability, provided that it can be related to a spatially differentiated survey and monitoring of ecosystem services. Giving high priority to the wise management of landscape accessibility implicitly puts a high degree of responsibility on design science to ensure a long run sustainable multifunctional land use. However this presupposes the inclusion of social science related to the study of social conflicts, of land use and trends in property rights, as well as of spatial behavior among different users of the landscape.

\section{The tourist carrying capacity of protected areas}

In the following, a study of landscape sustainability in and around protected areas in the Baltic region will be presented.

The main challenge for the sustainable development of tourism in protected areas is to balance the flow and behavior of visitors with the protection goals set up for the area. This is based on the need to combine the protection of nature and cultural resources on the one hand with the fulfillment of visitors' expectations to ensure visitor satisfaction on the other hand (Garthe 2005; Manning 2011).

This balancing is in principle related to the work on carrying capacity of the protected area or parts of it (Manning 2007). How many tourists can visit a place without threatening the protected nature values or spoil the experience for each other? There is no simple answer to this question, which is closely linked both to the protected nature system, the related social system and the mediating management system that has to ensure the sustainable functionality of the protected area (Manning and Lime 1996).

Although the determination of carrying capacities can be established through scientific investigation, carrying capacities are basically a result of political decision processes among stakeholders, balancing use and protection. Here experiential cognition might play a crucial role, but empirical evidence, provided through scientific methods, supported by monitoring of visitor flow and resource responses can qualify the determination and deliver a measuring system that can serve as a common denominator in the political process (Garthe 2005; Brandt 2010; Brandt and Holmes 2011).

The concept of carrying capacity is not a new invention related to the modern ecological crisis (Meadows 1972; Constanza 1997) or the modern discussion on the tragedy of the commons (Hardin 1968; Rodgers et al. 2011). It has been known in all stable traditional land use systems and was a central concept in the regulation of the most agricultural systems all over Europe in Medieval times. In these systems, the concept of carrying capacity was established for taxation purposes as a result of a political process supported by experience.

Historical studies also shows that such principles concerning carrying capacity for the ecological balanced use of the landscapes only worked if the overall goal, namely to ensure the longsighted sustainable use of the landscape, was commonly recognized and accepted among the stakeholders (Brandt 2010). If this goal was neglected in favor of narrow short-termed economy or power related considerations, it was not possible to ensure a sustainable land use based on principles of carrying capacity. As a modern study of historical land use systems concludes, Mediation among stakeholders is irrelevant if it is based on 
ignorance of the integrated character of nature and people (Gunderson and Holling 2002).

This is the main reason why general models for sustainability of protected areas are so difficult to develop. The variation in interests among stakeholders is considerable. Long termed ecological considerations are not always known or taken into account. The knowledge of visitor flows and their possible impacts is often limited. Therefore, a general acceptance of the ecological necessities and the social practice forming a foundation for a common management of carrying capacities are seldom realized, although ideologies, concepts and buzzwords on sustainability are often used noncommittal at the political level.

However, a protected area, perceived as a landscape designated to fulfill protection purposes by authorities, strongly interested in respecting these goals in continued cooperation among the relevant local stakeholders, might fulfill the conditions of using carrying capacity as a management instrument, provided that the stakeholders respect the goals too, or that the authorities have means and will to ensure that these goals will be respected among the stakeholders.

\section{The Baltic parks and benefits project}

The mutual benefits of protected areas and their regions concerning a long termed change of leisure activities in a sustainable direction has been emphasized in Europe during the last decade (Job and Metzier 2005; Mose 2007; Mayer et al. 2010).
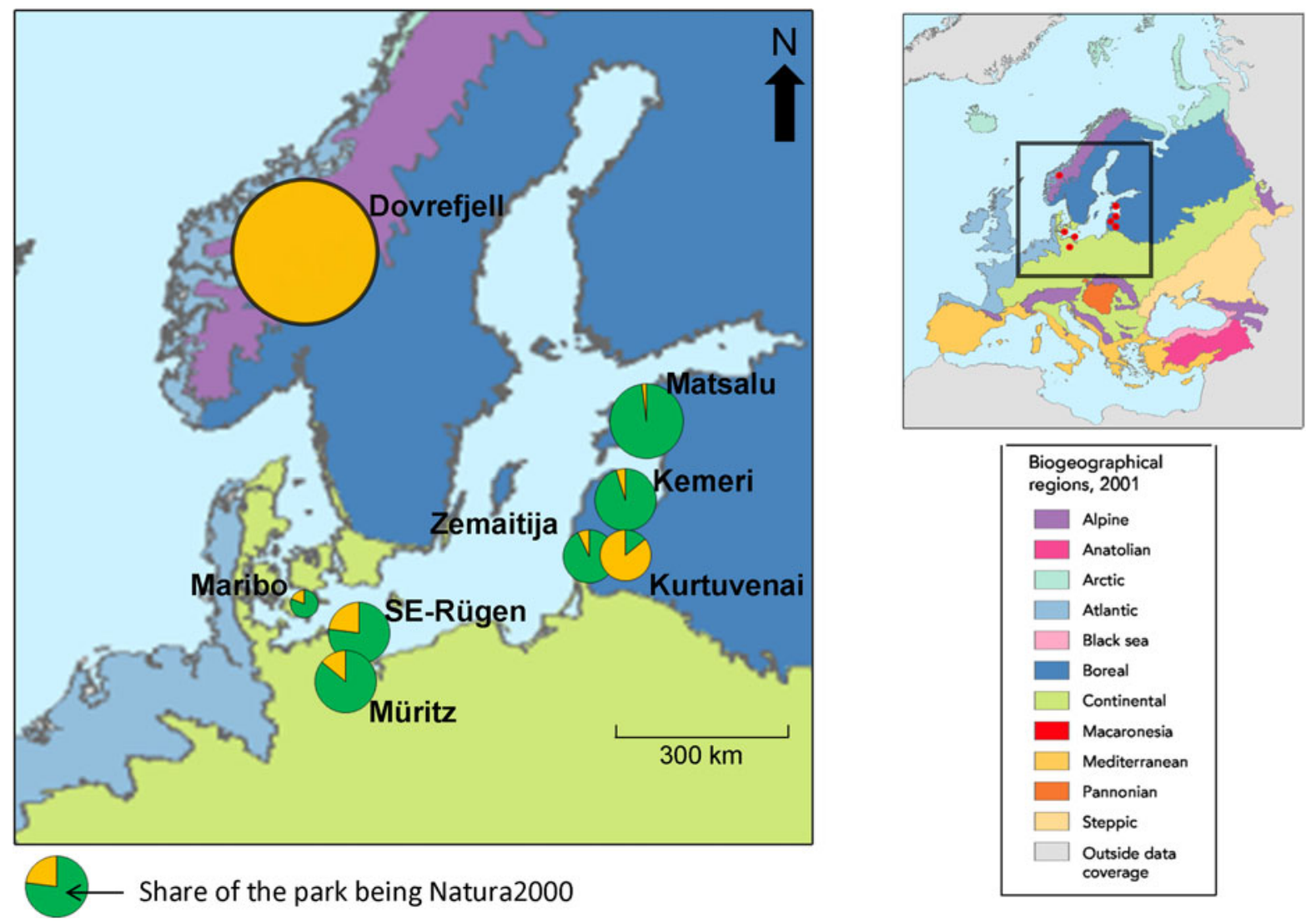

Fig. 2 The location of the eight protected areas selected for the Baltic Interreg project Parks and Benefits, in relation to a biogeographical regionalization of Europe. The areas of the circles are proportional with the size of the Nature Parks. Only Dovrefjell National Park in Norway is located outside the European Union. For the seven protected areas in the European Union the share of the park being designated as Natura 2000 area has been indicated as well. Source Extraction from the EU Natura 2000 Database for habitat sites overlapping the 7 EUparks of Parks \& Benefits. European Environmental Agency (EEA): Biogeographical regions, Europe 2001. http://www. eea.europa.eu/data-and-maps/figures/biogeographical-regionseurope-2001 
The European Union has set up a Baltic Interreg project called Parks \& Benefits (2009-2012) that seeks to promote regional co-operation on the development of an integrative and harmonized sustainable spatial planning. The project focuses on linking protected areas to their region in efforts to combine nature protection and sustainable tourism and recreation. It seeks to facilitate a network of eight large protected areas (see Fig. 2), regional authorities, stakeholders in tourism \& environment and universities, backed by the European Federation of Nature Parks, EUROPARC comprising 400 European protected areas. The EUROPARC federation promotes a European Charter of Sustainable Tourism (Parks \& Benefits 2010).

For this study, we have chosen to take our departure in the strong political commitment to the UN Biodiversity Convention, being implemented within the Natura 2000 network of the European Union. It appears that for most of the parks within the EU, the Natura 2000 sites (habitat and/or bird site areas) cover the vast majority of the protected area.

The pressure from the local population, tourism and regional visitors differs enormously among the parks (see Table 1). It is estimated that the human pressure on the protected areas varies from 10 overnight stays per square $\mathrm{km}$ land and year in Dovrefjell National Park in Norway to almost 20,000 in South East Rügen Biosphere Reserve. These are at the ends of two extremes and provide cases for the study of tourist carrying capacity and show the huge spatial differences between the parks.

Visitor related problems for wildlife exist in all the protected areas, even in the extensively used (but also very publicly open) Dovrefjell National Park. At the same time, in all the parks the vast majority of the vulnerable nature resources are well protected against visitor related threats, even in the intensely used (but also very fragmented and partly inaccessible) South East Rügen Biosphere Reserve.

In relation to the historical experiences with carrying capacity in Europe, it is important to keep in mind that the carrying capacity for tourism in protected areas is a matter of visitor flow. The varied geographical structure of the protected area (land cover and land use composition, infrastructure capabilities, different kinds of accessibility, barriers and information design) can mostly offer strong instruments for a management strategy being oriented toward finding a balance between visitor flow and resource protection.

The social, experiential problems - the man-man conflict related to crowding in outdoor recreation (Manning 2011)—might, however, be much more difficult to solve.

\section{A case study of local landscape accessibility}

Thus, carrying capacity has obviously to be specified in much more detail as a concrete relation between (1) specific protection goals set up for the individual local conflict area that can be delineated around the individual protected habitat or nature site within the protected area, (2) the consideration of other relevant stakeholder interests, and (3) the management opportunities and capacities concerning regulation of the visitor flow at a higher park level (Brandt 2011).

Within the Natura 2000 sites there might be several hundred small areas of listed habitat sites in relation to which a potential local nature protection conflict area can be delineated. Of the 231 listed habitat types to be protected within the European Union, defined in the EU Habitat Directive, 55 (24\%) can be found within at least one of the seven parks (Brandt and Holmes 2011). Both the protection and the experience of these special protected habitats are totally dependent on their accessibility.

Landscape accessibility is a multifaceted concept, comprised of physical, social, legal and symbolic aspects (Semm and Palang 2010). A detailed study of accessibility of 226 of such areas in total representing 12 different listed habitat types in the Natura 2000 site of Maribo Lakes Nature Park in Denmark was made in 2011. It shows a complex pattern of accessibility to the habitats and the surrounding areas, providing relatively good protection for the habitats against visitor pressure: Up to one-third of the sites-and among them the vast majority of the vulnerable wet habitat sites-are in practice not accessible to the public, although they certainly can be threatened by other impacts. Different kinds of accessibility to the protected habitat types have been mapped to serve as management tools for the monitoring of potential tourist-induced nature protection conflict areas related to the specific habitat type areas. An example is shown in Fig. 3 and Table 2. 


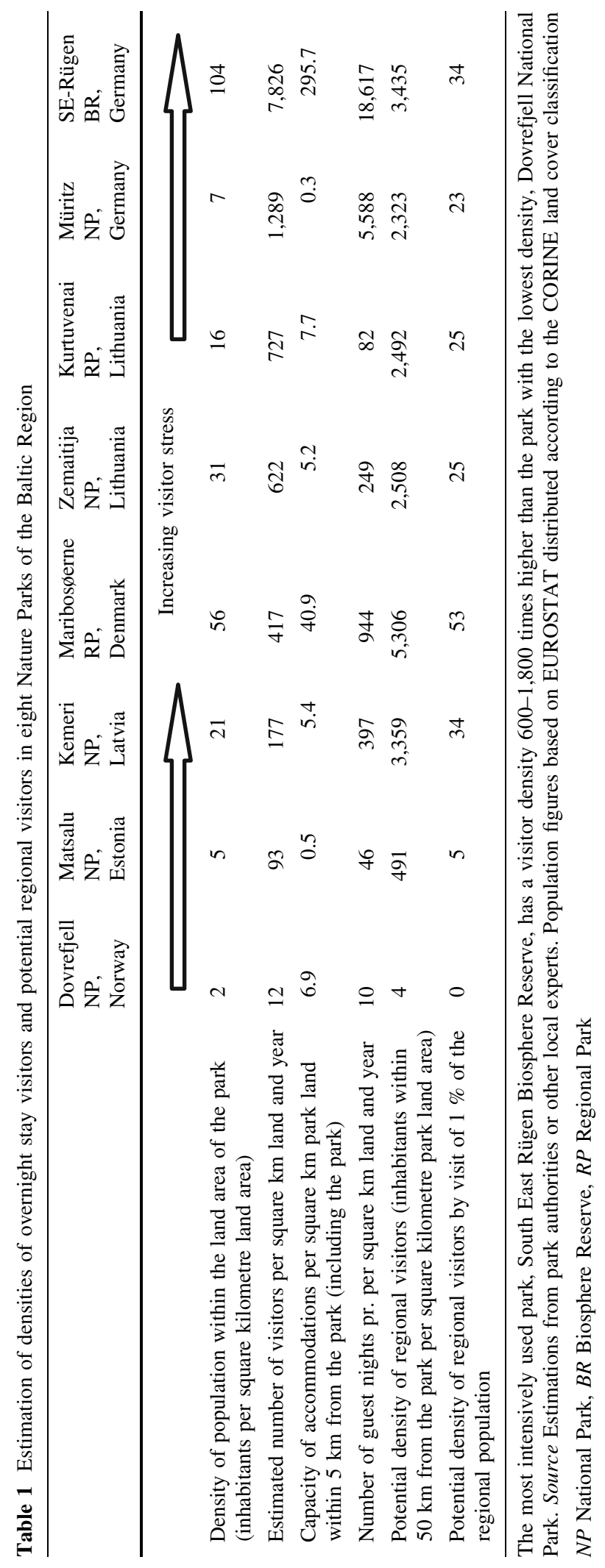


As a general result, one of the most important means for visitor regulation to protect the nature resources in such areas seems to be the wise planning and management of hiking and biking tracks, combining the opportunities for the attraction to exiting nature experiences with an efficient distraction from selected fragile habitats.

Thus, ironically the biggest challenge for the management of sustainable tourism in protected areas seems to be in areas with fragile nature resources without layout of infrastructural connections. In the intensively used parts of Europe this is primarily related to open water, lakes or sea inlets, where visitor movements might be difficult to regulate for physical, juridical and political reasons. However, a detailed vulnerability plan for Maribo Lakes Nature Park in Denmark has rather successfully concentrated on the regulation of sailing on the lakes (Nielsen 2004).

Interestingly the main visitor-nature protection conflict in Dovrefjell is related to the access to the tracking routes of the local stock of wild reindeer in the upper mountains of Dovrefjell. To protect the wild reindeer, the Norwegian Parliament has decided to close a former military road to the top of the Snфhetta mountain which is a popular tourist destination. Many opponents have argued that the abandonment of channeled traffic into the area would increase pressure elsewhere, as people would walk in vulnerable areas rather than using the road (Kaltenborn et al. 2011).

\section{Conclusion}

Before the development of capitalism, conceptual frameworks which saw man and nature as being an integrated whole were widespread throughout the world. During capitalism these frameworks were suppressed by non-sustainable productive ideologies. This affected the conceptual frameworks of socialist development after the Russian revolution and during the cold war. Important knowledge for modern sustainability has, however, survived through land use practice that should be studied in priority to conceptual constructs by the endeavor to develop a landscape ecology for landscape sustainability.
Fig. 3 The two maps show the variation in physical and communicative accessibility to Nature 2000 habitats in Nature Park Maribo Lakes. The concept of physical accessibility deals with physical obstacles of access on foot, by bike, car or boat (to the islands in the lakes). The communicative accessibility index has been calculated by mapping direct and indirect communication connected to the habitats and the surrounding area. Direct communication relates to communication of accessibility in text or symbols, such as signage. Indirect communication is about landscape elements or infrastructure such as parking lots, benches, fences, houses etc. either inviting or prohibiting access to the area around the habitat. All habitats have been added a score between 1 (very clear invitation to access) and 5 (very clear rejection of access) for both the direct and indirect communication. The values for the two scores have been merged and then divided by 2 in order to calculate an overall index of communicative accessibility. One example could be a sign communicating a clear prohibition of access to a field road leading to a habitat. The overall communicative index of the habitat is 4 . This is because the habitat will be given the value of 5 (clear rejection of access) in connection to the direct communication of access by the sign and the value of 3 (mixed communication of access) in the indirect category, because, the road still invites to some kind of access and might even be a road with public access according to the legislation. In this example the overall score will be calculated as $[(5+3) / 2=4]$

Throughout history, an experience based use of the concept carrying capacity for regulation of a few types of land use has been widespread all over the world. Today, the concept is often used in the management of visitor flow in publically owned protected areas with tourism being the dominant land use. In a wider perspective of locally balanced sustainable development of old cultural landscapes with complicated accessibility as in Europe, the concept of carrying capacity is still relevant as an overall analytical tool, as shown by a comparison of eight protected areas in the Baltic region. However, through a detailed analysis in one of the protected areas, the problem of carrying capacity dissolves into a variety of specific spatial contexts and conflicts with crucial influence on the carrying capacity at different spatial levels. Here conceptual considerations of different kinds of landscape accessibility seem more central for landscape sustainability than carrying capacity. Additionally, the landscape sustainability of protected areas and their regions in Europe has to include many other landscape and stakeholder considerations than optimizing visitor flows. 
A

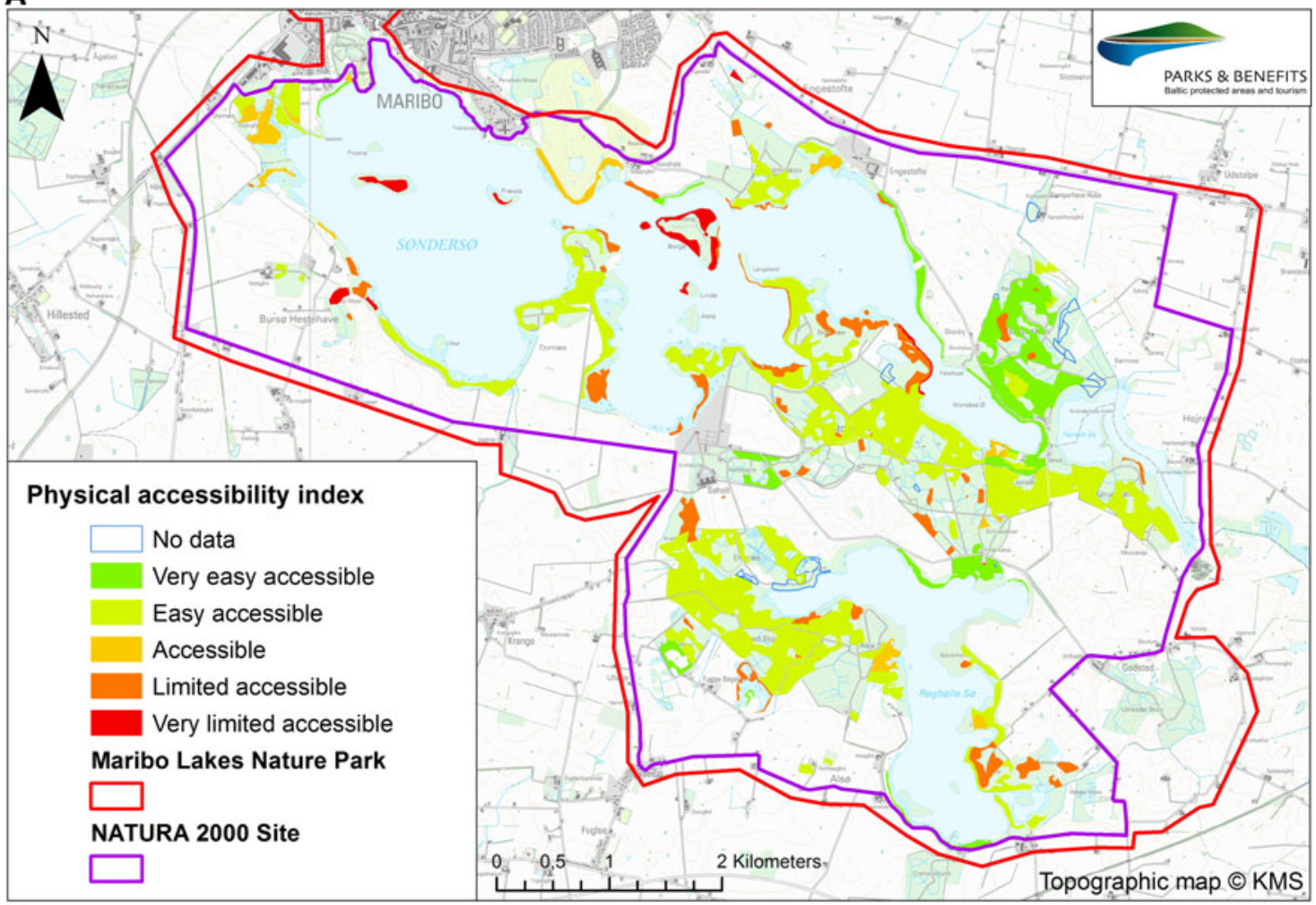

B

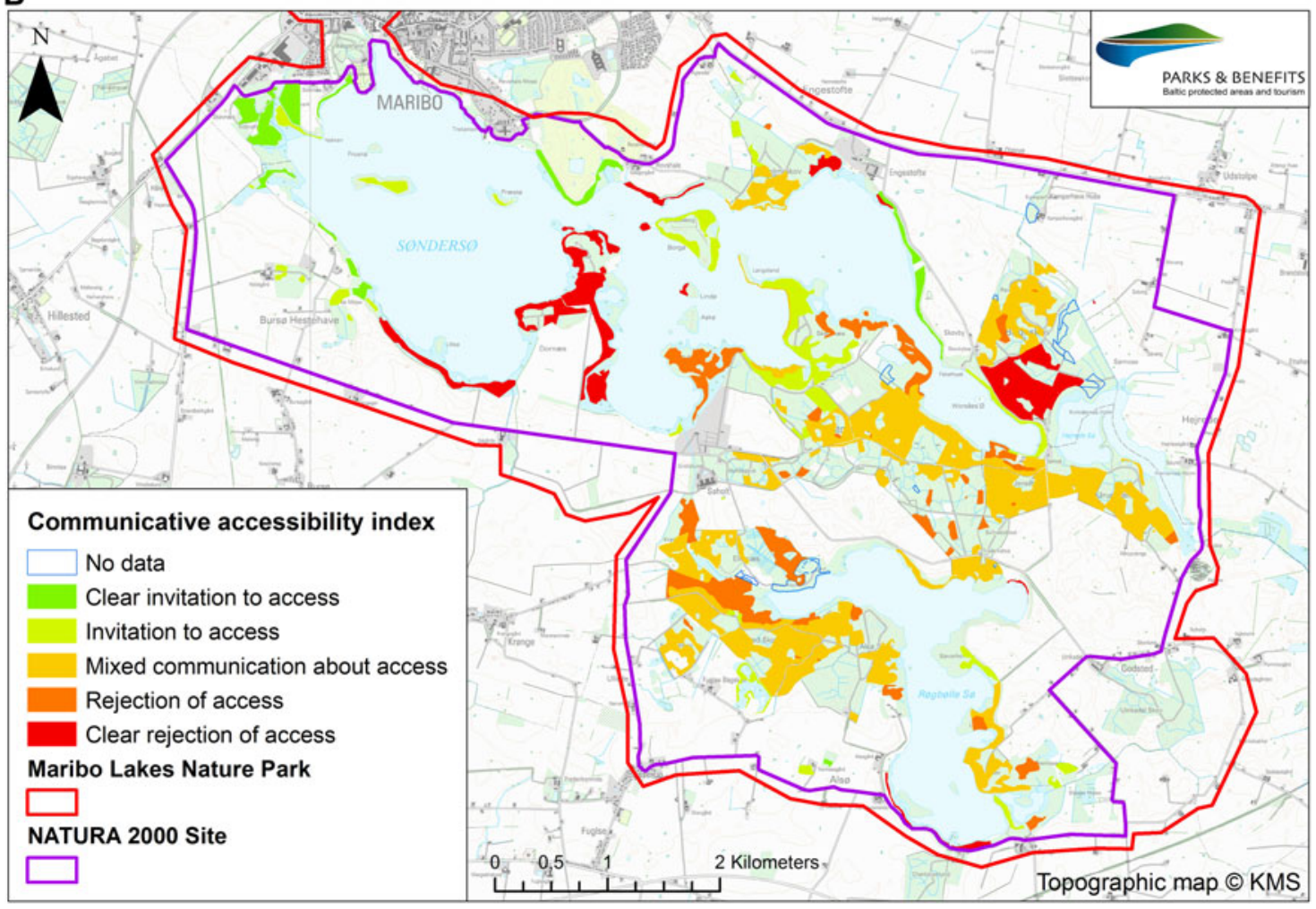







Acknowledgments We would like to thank three anonymous reviewers for several constructive proposals for improvement, and Andrew Crabtree, ENSPAC, Roskilde University for a detailed linguistic correction and many relevant questions about the formulations of a number of arguments.

\section{References}

Brandt J (1998) Key concepts and interdisciplinarity in landscape ecology: a summing-up and outlook. In: Dover JW, Bunce RGH (eds) Key concepts in landscape ecology. IALE, Preston, pp 421-434

Brandt J (2005) Globalisation, sustainable development and competencies of landscape change in a European perspective. Alfa Spectra 2(2005):10-14

Brandt J (2010) Sustainability as a tug of war between ecological optimisation and social conflict solution. In: Nielsen KA, Elling B, Figueroa M, Jelsøe E (eds) A new agenda for sustainability. Ashgate Publishing Limited, Farnham, pp 43-62

Brandt J (2011) Carrying capacity-how much tourism can protected areas cope with? In: Ostermann $\mathrm{O}$ (ed) Guide to sustainable tourism in protected areas. Ministry for Agriculture, Environment and Consumer Protection Mecklenburg-Vorpommern, Schwerin, pp 26-35

Brandt J, Holmes E (2011) Conditions for the management of carrying capacity in the parks of Parks \& Benefits. Dept. of Environmental, Social and Spatial Change (ENSPAC), Roskilde University, Roskilde

Brandt J, Vejre H (2004) Multifunctional landscapes-motives, concepts and perspectives. In: Brandt J, Vejre $\mathrm{H}$ (eds) Multifunctional landscapes, vol 1. WIT Press, London, pp 3-31

Chen X, Wu J (2009) Sustainable landscape architecture: implications of the Chinese philosophy of "unity of man with nature" and beyond. Landscape Ecol 24:1015-1026

Constanza R (1997) An introduction to ecological economics. St. Lucie Press, Boca Raton

Council of Europe (2000) European landscape convention. http://conventions.coe.int/Treaty/en/Treaties/Html/176. htm. Accessed 16 July 2012

Dallara A, Rizzi P (2012) Geographic map of sustainability in Italian local systems. Reg Stud 43(3):321-337

Flyvbjerg B (2011) Case study. In: Denzin NK, Lincoln YS (eds) The Sage handbook of qualitative research. Sage, Thousand Oaks, pp 301-316

Garthe C (2005) Tourismus und Sport in Schutzgebieten. Tragfähigkeitsanalysen und Besucherbegrenzungen als Managementansatz. Universität Hannover, Hannover

Gunderson LH, Holling CS (eds) (2002) Panarchy. Understanding transformations in human and natural systems. Island Press, Washington

Hardin G (1968) The tragedy of the commons. Science 162(3859):1243-1248

Job H, Metzier D (2005) Regionalökonomische Effekte von Gro $\beta$ schutzgebieten. Natur und Landschaft 80(11):465-471

Kaltenborn BP, Qvenild M, Nellemann C (2011) Local governance of national parks: the perception of tourism operators in Dovre-Sunndalsfjella National Park, Norway. Nor J Geography 65:83-92

Manning RE (2007) Parks and carrying capacity. Commons without tragedy. Island Press, Washington

Manning RE (2011) Studies in outdoor recreation. Search and research for satisfaction. 3rd edn. Oregon State University Press, Corvallis

Manning R, Lime D (1996) Crowding and carrying capacity in the National Park System: toward a social science research agenda. In: Crowding and congestion in the National Park System: guidelines for management and research, vol 86 . University of Minnesota Agricultural Experiment Station Publication, St. Paul, pp 27-65

Mao Z (1937/1990) Dialectical materialism (lecture notes). In: Knight N (ed) Mao Zedong on Dialectical materialism. M.E. Sharpe, New York, pp 84-131

Marx K (1867/1967) Capital, vol 1. International Publishers, New York

Mayer M, Müller M, Woltering M, Arnegger J, Job H (2010) The economic impact of tourism in six German national parks. Landsc Urban Plan 97(2):73-82

Meadows DH (1972) The limits of Growth. A report for the club of Rome's project on the predicament of mankind. Universe Books, New York

Mose I (ed) (2007) Protected areas and regional development in Europe. Studies in environmental policy and practice. Ashgate, Farnham

Musacchio LR (2009a) The ecology and culture of landscape sustainability: emerging knowledge and innovation in landscape research and practice. Landscape Ecol 24:989992

Musacchio LR (2009b) The scientific basis for the design of landscape sustainability: a conceptual framework for translational landscape research and practice of designed landscapes and the six Es of landscape sustainability. Landscape Ecol 24:993-1013

Nielsen UB (2004) Sårbarhedsplan for Naturpark Maribosøerne [Vulnerability Plan for Maribo Lakes Nature Park]. Storstrøms Amt

Parks \& Benefits (2010) On tour to the natural treasures around the Baltic sea. www.parksandbenefits.net. Accessed 16 July 2012

Potschin M, Haines-Young R (2006) Landscapes and sustainability. Landsc Urban Plan 75(3-4):155-161

Rodgers CP, Straughton EA, Winchester AJL, Pieraccini M (2011) Contested common land. Environmental governance past and present. Earthscan, London

Semm K, Palang H (2010) Landscape accessibility: spaces for accessibility or spaces for communication? Living Rev Landsc Res 4(4):24

Stalin JV (1938) Dialectical and historical materialism. International Publishers Company, New York

Stenseke M, Jones M (2011) Conclusion: benefits, difficulties, and challenges of participation under the European landscape convention. In: Jones M, Stenseke M (eds) The European landscape convention. Challenges of participation. landscape series, vol 13. Springer, Dordrecht, pp 295-307. doi:10.1007/978-90-481-9932-7_15

Suškevičs M, Külvik M (2011) The Role of information, knowledge, and acceptance during landowner participation in the Natura 2000 designations: the cases of Otepää and 
Kõnnumaa, Estonia. In: Jones M, Stenseke M (eds) The European landscape convention. Challenges of participation. landscape series, vol 13. Springer, Dordrecht, pp 275-294. doi:10.1007/978-90-481-9932-7_14

Wiens JA (2009) Landscape ecology as a foundation for sustainable conservation. Landscape Ecol 24:1053-1065

World Commission on Environment and Development (1987) Our common future. Oxford University Press, Oxford

Wu J (2010) Landscape of culture and culture of landscape: does landscape ecology need culture? Landscape Ecol 25:1147-1150
Wu J, Hobbs R (2002) Key issues and research priorities in landscape ecology: an idiosyncratic synthesis. Landscape Ecol 17:355-365

Yin RK (1994) Case study research: design and methods. Sage, London

Zhao J, Woudstra J (2007) 'In agriculture, learn from Dazhai': Mao Zedong's revolutionary model village and the battle against nature. Landsc Res 32(2):171-205 